\title{
REVOLUÇÃo PERIFÉRICA: A PRÁTICA DO SKATE NO EXTREMO LESTE PAULISTANO ${ }^{1}$
}

\author{
Giancarlo Marques Carraro Machado ${ }^{2}$
}

\section{Citadinidades em São Paulo}

A Zona Leste paulistana apresentou nas últimas décadas um considerável processo de reestruturação de sua paisagem que impactou de maneira contundente o cotidiano de seus habitantes. Com a efetivação de políticas públicas e de demais tipos de iniciativas, a região vem passando por uma espécie de reconversão econômica fomentada pelo estabelecimento de projetos sociourbanísticos e pela justaposição, ainda que de forma difusa, de grandes empreendimentos vinculados ao setor terciário, como a construção de shoppings centers, centros comerciais, hotéis, redes de hipermercados, arena esportiva etc. Tudo isso tem contribuído para reposicioná-la estrategicamente em escalas mais amplas - conforme ficou evidente, por exemplo, em momentos prévios à Copa do Mundo FIFA de 2014, quando muito se falou da centralidade criada em torno de Itaquera, distrito que abriga a chamada Arena Corinthians ${ }^{3}$-, condição que não exclui, todavia, a persistência de enclaves em que se revelam notáveis desigualdades e segregações a partir das quais se estabelecem as "tramas da cidade” (Telles e Cabannes, 2006) que entrelaçam práticas que extrapolam as fronteiras do legal e ilegal, ${ }^{4}$ como já abordado etnograficamente por pesquisas detidas sobre esta região (Feltran, 2005, 2011; Hirata, 2010; D’Andrea, 2013; Spaggiari, 2015 etc.).

\footnotetext{
${ }^{1}$ Este artigo é derivado da tese de doutorado "A cidade dos picos: a prática do skate e os desafios da citadinidade”, defendida em 2017 no âmbito do Programa de Pós-Graduação em Antropologia Social da Universidade de São Paulo (PPGAS/USP) sob a orientação do Prof. Dr. José Guilherme Magnani. A pesquisa contou com financiamento da Fundação de Amparo à Pesquisa do Estado de São Paulo (FAPESP, processo 2012/23331-0).

${ }^{2}$ Universidade Estadual de Montes Claros (Unimontes-MG), Brasil.

${ }^{3}$ Também conhecida como Itaquerão. Para mais detalhes sobre as implicações da construção desta arena esportiva entre os torcedores, ver Toledo (2013).

${ }^{4}$ É nas "tramas da cidade", para utilizar os pressupostos de Telles eCabannes (2005: 16-17), "que os lances da vida são jogados, é aí que se processam as exclusões, as fraturas, os bloqueios, e também as capturas na hoje extensa e multifacetada malha de ilegalidades que perpassam a cidade inteira e que operam, também elas, como outras tantas formas de junção e conjugação da trama social. Aí também os elos perdidos da política, tragados que foram pelo princípio gestionário que trata das 'pontas', da dita governança econômica e, de outro lado, da gestão do social e administração de suas urgências”.
}

Iluminuras, Porto Alegre, v. 19, n. 47, p. 71-93, dec, 2018. 
A Zona Leste é um “território de rupturas e permanências” (Rolnik e Frúgoli Jr., 2001), características que se revelam em vários planos. As tantas transformações e intervenções lá ocorridas nas últimas décadas contribuíram para banir, ordenar ou embaralhar certos usos que se processam em espaços e equipamentos dispostos em seus limites. Entretanto, de igual modo, é possível considerar que o seu processo de urbanização também viabilizou o florescimento de uma série de práticas citadinas que vem consolidando novas formas de ativismos que ora rechaçam ora se coadunam a determinadas pretensões econômicas, políticas e urbanísticas. Tal constatação ficou evidente a partir do instante em que passei a acompanhar o cotidiano de um distrito localizado no extremo leste de São Paulo ${ }^{5}$.

O distrito de Cidade Tiradentes, ao contrário de outras periferias da cidade, "representa uma área com problemas urbanos decorrentes não da ausência do Estado, mas da presença deste no âmbito local” (Frúgoli Jr. apudHikiji e Caffé, 2013: 20). A partir da atuação estatal foi elaborado um considerável conglomerado de habitações populares, as COHABs, cujas lógicas gerenciais foram pensadas para atender a certas estratégias do poder público para São Paulo. ${ }^{6}$ No entanto, conforme também assinalou Frúgoli Jr. (apudHikiji e Caffé, 2013: 20), tais ganhos habitacionais não vieram acompanhados por uma urbanização mais consistente, ${ }^{7}$ logo, com a escassez de espaços que permitissem a constituição de formas de sociabilidade mais duradouras, muitas práticas citadinas locais passaram a se aproveitar das ruas como importantes loci de atuação. Em razão disso, no distrito que já fora tratado como uma “cidade-dormitório”, perpetuou-se uma agitada vida pública que vem, há anos, ocupando diuturnamente as suas ruas, praças, becos, terrenos baldios, enfim, toda sorte de espaços disponíveis. A batida do funk atrai centenas e até milhares de jovens em bailes ensurdecedores que varam a madrugada; motoqueiros transitam velozmente pelos asfaltos fazendo barulho e peripécias com as suas respectivas motos; rodas de samba agitam vielas; grafiteiros e

\footnotetext{
${ }^{5}$ Realizei trabalho de campo na região leste de São Paulo no decorrer de 2015.

6 A Companhia Metropolitana de Habitação de São Paulo (COHAB-SP) foi criada em 1965 com a finalidade de favorecer o acesso à habitação digna à população de menor renda, obedecendo às normas e critérios estabelecidos pelo Governo Municipal e pela legislação federal. Mais informações: http://cohab.sp.gov.br/. Acesso em 08/08/2016.

${ }^{7}$ De acordo com Barone (2013: 76), “a ocupação da Zona Leste ocorreu a partir dos núcleos ferroviários, constituindo cidades-dormitório, desde o início de sua urbanização. O crescimento vertiginoso desses núcleos-dormitório acabou por formar uma imensa mancha urbana, circundando a região central da cidade, dela dependente, desprovida de usos que garantissem um desenvolvimento econômico local, e com um padrão de ocupação extremamente precário”.
} 
pichadores não medem esforços para deixarem suas marcas em muros e paredes; baloeiros se esquivam dos riscos para fazer seus balões voarem sem destino; pipas empinadas colorem os céus; batalhas de rap reverberam angústias e anseios;rolezinhos promovidos por adolescentes agitam shopping centers e parques; o futebol de várzea, por sua vez, estabelece animadas contendas tanto em “terrões” quanto em gramados sintéticos; o público evangélico não cessa seus louvores; já os saraus dão novas perspectivas e formatos às narrativas periféricas ao passo que os coletivos audiovisuais registram às suas maneiras o cotidiano das quebradas. Enfim, a vida citadina pulsa na Zona Leste.

A prática do skate, assim como as demais acima citadas, se faz presente com muito vigor no extremo leste. As suas dinâmicas locais revelam características que perpassam o universo do skate em escala mais ampla, como a predisposição para circulação pela cidade (rolês) e apropriação de equipamentos urbanos (picos) $^{8}$, conforme já abordei em pesquisas anteriores (Machado, 2014; 2017). Contudo, essas regularidades são acomodadas a outras experiências citadinas que fazem parte do cotidiano juvenil das quebradas paulistanas, ${ }^{9}$ como a valorização das ruas como espaço de criação, além de “sociabilidades alargadas” (Agier, 1999) para outros contextos. ${ }^{10} \mathrm{~A}$ articulação entre rua e sociabilidade se expressa por meio da formação de coletivos que buscam afirmar o pertencimento de seus integrantes a um bairro ou a uma região da cidade. ${ }^{11}$ Estas são mobilizações, tal como já problematizado por outras pesquisas

\footnotetext{
${ }^{8}$ Pico é uma categoria nativa. Refere-se a equipamentos urbanos (como bancos, corrimãos, hidrantes, quinas, bueiros, paredes, bordas de concreto, inclinações etc.) que são avaliados pelos praticantes em função de suas texturas, inclinações e asperezas, que, a depender de certas condições materiais, permitem a realização de manobras, ou seja, de técnicas corporais realizadas com um skate.

${ }^{9} \mathrm{O}$ termo quebrada é uma gíria paulistana utilizada sobretudo por jovens moradores de periferias. Segundo Pereira (2007: 241), ao fazer uma aproximação com as categorias propostas por Magnani (2007), “a ideia de 'quebrada' contém esses elementos da categoria pedaço, mas também designa uma forma de apresentá-lo para quem é de fora, mostrando-o como um lugar hostil e perigoso para quem não pertence a ele, nem conhece suas regras. A noção de 'quebrada' é também associada à ideia de um bairro periférico, pobre, com altos índices de violência, onde as normas de conduta não devem ser desrespeitadas".

${ }^{10}$ Por meio das "sociabilidades alargadas" (Agier, 1999) os skatistas constroem uma série de mediações que os permitem acessar redes mais amplas de relacionamentos, em que suas escolhas e decisões são seletivas, propiciando-os a estabelecer relações com instituições mais abrangentes, como o poder público.

${ }^{11}$ D'Andrea (2013: 16) considera que "a partir da década de 1990, uma série de coletivos artísticos surgiram nos bairros periféricos de São Paulo. Quatro foram os principais motivadores para esse fenômeno: a possibilidade de fazer política em um contexto de descenso de movimentos sociais e dos partidos políticos; a luta por pacificação; a necessidade de sobrevivência material, da qual a produção artística se revelou como uma possibilidade e; a arte como emancipação humana. Por sua ação e discursividade, estes coletivos exaltam o orgulho periférico do mesmo modo que são fenômenos
} 
(Nascimento, 2011; D’Andrea, 2013; Aderaldo, 2013), que também trazem um reposicionamento semântico de conceitos caros à pauta antropológica, como a noção de “periferia” e “cidadania”, além de novas perspectivas que redefinem certas hierarquias impostas pelas governanças urbanas junto à populações consideradas marginalizadas. ${ }^{12}$

Em Cidade Tiradentes, bem como nos demais distritos da Zona Leste, há diversos coletivos que atuam em várias frentes, sejam elas artísticas, musicais, audiovisuais, educacionais etc., e que reverberam as "novas subjetividades periféricas”(D’Andrea, 2013). Dentre eles destaca-se ao menos um cujo princípio de ação é orientado pelas experiências compartilhadas no universo do skate: trata-se do coletivo Love CT, que constitui o foco das análises apresentadas neste artigo. Ao levar em conta a atuação de tal coletivo, objetiva-se, com efeito, problematizar como jovens skatistas resistem a certas relações de poder, assimetrias, desigualdades e segregações que calham na região leste de São Paulo e como eles se impõem em múltiplos espaços a partir de suas manobras e táticas a fim de garantir as suas práticas citadinas e inserções na cidade.

\section{Love CT: manobras citadinas}

O Love CT é um coletivo formado por skatistas residentes em Cidade Tiradentes, quais sejam,Anderson Lucas, Marcelo Martins, Elton Melonio, Denis Silva e Daniel Feitosa. ${ }^{13} \mathrm{O}$ contato de cada um com o skate começou há pelo menos uma década. Por conta de seus comprometimentos com a prática, todos são reconhecidos por deterem técnicas aguçadas que se expressam por meio de seus respectivos leques de

decorrentes desse orgulho". Todas estas motivações corroboram com a atuação do Love CT em Cidade Tiradentes.

12 É válida a constatação de que “a partir da década de 1990, a condição de ser habitante de bairros periféricos começa a ser elaborada no registro do orgulho de ser periférico. Este processo foi encabeçado, sobretudo, pela parcela jovem e negra da população, e se alastrou para todos os outros setores das classes populares” (D'Andrea, 2013: 19). Desse modo, as ações dos coletivos atuantes em regiões periféricas, como o Love CT, “tem por pressuposto uma mudança na subjetividade da população periférica (...). Esta nova subjetividade, cujo cerne reside no reconhecimento da própria condição, na potencialidade dessa condição e no orgulho dessa condição, quando aciona o agir político, transforma o indivíduo em sujeito periférico" (D'Andrea, 2013: 19).

${ }^{13}$ Em dezembro de 2015 tive a oportunidade de acompanhar o cotidiano do skate em Cidades Tiradentes. Participei, inclusive, da gravação de um episódio da série “Causando na Rua”, sob direção geral da cineasta Tata Amaral, cujo foco era a atuação do coletivo Love CT. A ocasião me permitiu desvelar diversas perspectivas sobre os sentidos que a prática do skate adquire nesta região periférica da cidade. Tais momentos foram importantes para estabelecer novos contatos ou manter aqueles já firmados com os skatistas do distrito. 
manobras. Anderson Lucas, Marcelo Martins e Daniel Feitosa ainda são amadores, ao passo que Denis Silva e Elton Melônio são profissionais de relativo destaque na categoria street skate(skate de rua). Estes últimos, por exemplo, já tiveram a oportunidade de participar de competições nacionais e internacionais (obtendo, inclusive, boas colocações), de figurar em matérias produzidas por diversas mídias especializadas e de realizar turnês por vários países europeus. Em conjunto, os skatistas do Love CT são responsáveis por fomentar o skate não apenas em Cidade Tiradentes, mas também na região leste paulistana. A revista Tribo Skate, em matéria especial sobre o coletivo, destacou:

Eles contrariam a ordem natural e fazem uma das cenas mais verdadeiras e ativas do skate nacional com as próprias mãos. Mesmo com todas as piores circunstâncias possíveis, o skate transborda nas ruas e esgotos da Cidade Tiradentes, um dos maiores guetos do Brasil. (Mug, Marcelo. "Love CT". Revista Tribo Skate, n. 212, 2013: 47)

A prática do skate na Cidade Tiradentes, conforme revelam os membros do Love CT, tem seus primórdios em fins da década de 1980, quando as ruas e demais equipamentos do distrito passaram a ser ocupados por diversos jovens. A circulação para outras partes da cidade era dificultada em razão das limitações em termos de transporte público e também devido ao preço das passagens das conduções. Marcelo Martins, skatista há 21 anos, revelou que "para ir ao Centro era difícil. Da minha época, muitos moleques foram ao Centro depois de adulto”. Muitos skatistas de Cidade Tiradentes ficavam restritos aodistrito em que moravam, portanto, a fim de obter um local de referência para as suas manobras, bem como para a manutenção de suas redes de sociabilidades, eis que alguns deles tiveram a iniciativa, em 1997, de ocupar e transformar um dado espaço conforme as suas próprias demandas. Na COHAB Prestes Maia havia uma área obsoleta ao lado de um campo de futebol, e, como o seu piso era liso, parecido com o de uma quadra esportiva, os skatistas resolveram produzir obstáculos de ferro e madeira para ali os colocarem. Formou-se, então, a pista de skate que mais tarde passaria a ser reconhecida como Pista do Maia, nome em referência à COHAB onde ela se localiza:

O skate em nossa comunidade sempre foi muito forte. Comecei a andar no final da década de 90, na pista do Prestes Maia, uma das mais famosas da Zona Leste. Quem 
fez a área foram os próprios skatistas. Com ajuda política eles ganharam o material de construção e fizeram tudo com as próprias mãos, sem mestre de obras e nem engenheiro. Apenas skatistas com boas influências no skate e visão de progresso. Em 1997 foi inaugurada a primeira pista de skate da Zona Leste. (Anderson Lucas, skatista amador, depoimento concedido à Revista Tribo Skate, n. 212, 2013: 50)

O surgimento da pista em questão se deu através de uma iniciativa gerida pelos próprios skatistas de Cidade Tiradentes e de outros distritos da Zona Leste. Como os obstáculos provisórios rapidamente se estragaram, houve uma nova mobilização para que eles fossem substituídos por rampas de concreto. Como o custo para as suas produções seria maior, os envolvidos com o empreendimento resolveram lançar mão de contatos com políticos (vereadores e deputados) que atuavam na região. Após conseguirem as verbas eles iniciaram, novamente por conta própria, a construção das rampas. Com isto a Pista do Maia foi reformulada, constituindo-se desde então como um importante ponto de encontro para praticantes de todo o leste paulistano. Lá aconteceram diversos eventos, sobretudo competições amadoras, que revelaram renomados praticantes de destaque em nível nacional, como os atuais profissionais Fábio Castilho, Diego Oliveira, Elton Melônio e Denis Silva. Sendo assim, graças aos esforços dos skatistas locais é que a prática do skate pôde se consolidar no extremo leste e repercutir no contexto metropolitano:

Das dificuldades, das paradas que a gente enfrentou, tivemos que inventar tudo. De tudo o skate já vinha sendo contado, das histórias, a gente sentia que a gente da CT [Cidade Tiradentes] era excluído. Da cena, do mercado, e com isto a gente começou a olhar para dentro e começamos a enxergar em nós mesmos as possibilidades. Até hoje vem sendo assim. (Marcelo Martins, skatista amador e educador do coletivo Love CT, entrevista em 2016)

A gente sempre fez os eventos e sempre veio muita gente de outras regiões, até caras do Rio de Janeiro. Isto se tornou uma referência para a Zona Leste, para os que não se enquadravam no Centro, nos grandes eventos, no lado profissional. A ZL, a partir da CT, deu uma puxada em eventos de skate na cidade. Como sempre veio gente de todos os lugares, e como sempre fomos bastante acolhedores... Essa comunicação foi muito forte com os rapazes que vinham nos visitar, e consequentemente a gente ia andar nos lugares onde eles andavam. A ZL se conversa, ela se respeita, não tem este lance do localismo. (Marcelo Martins, skatista amador e educador do coletivo Love CT, entrevista em 2016)

A Pista do Maia foi a primeira a ser construída em Cidade Tiradentes, sendo, ainda, uma das poucas existentes na cidade de São Paulo em meados da década de 1990. Após a sua construção o distrito recebeu, segundo interlocutores contatados, mais treze pistas de skate. Tais ganhos se deram a partir de 2003, quando a administração da então 
prefeita Marta Suplicy (PT, 2001-2004) implementou uma série de projetos sociais e urbanísticos para o extremo leste. Entretanto, quase todas as pistas atualmente estão em péssimo estado, com imperfeições no piso e nas rampas, condições que restringem os seus usos.

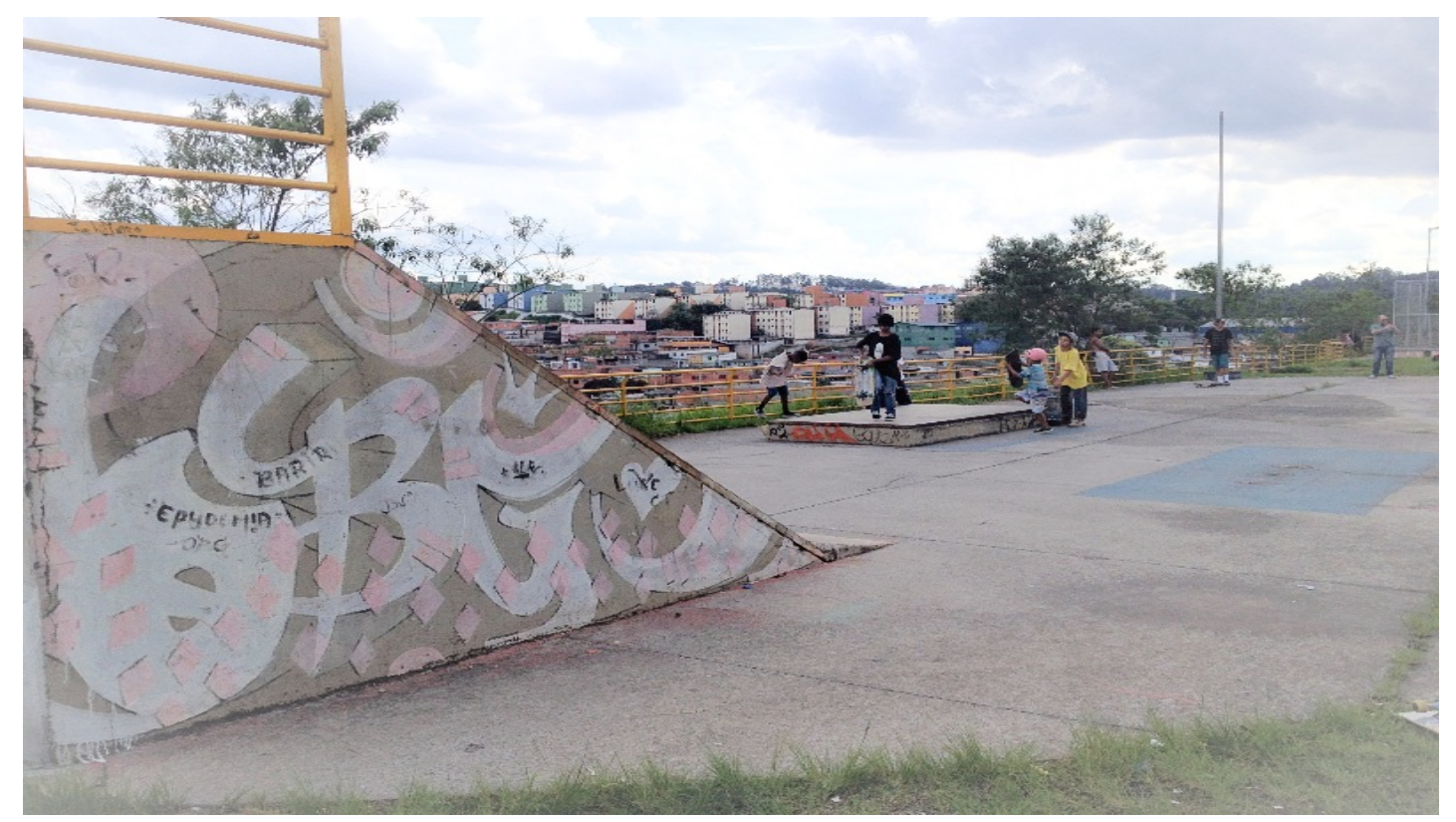

Imagem 1: Pista de skate em condições precárias disponível em Cidade Tiradentes (foto por Giancarlo Machado)

As pistas tornaram-se espaços requisitados para a prática corporal, todavia, elas não foram capazes de arrefecer, ao menos para uma parcela dos skatistas, certos tipos de experiências citadinas proporcionadas pelo skate no âmbito da Cidade Tiradentes. Os integrantes do coletivo Love CT, por exemplo, guardam muitas histórias de situações que ocorreram a partir de seus rolês pelo extremo leste da cidade. Por volta do ano 2005 a região passava por um clima de instabilidade em decorrência de conflitos entre bairros vizinhos. Havia muitas rixas por conta da manutenção de ilegalidades, principalmente do tráfico de drogas, que culminavam no estabelecimento de fronteiras territoriais e que impactavam as relações cotidianas dos moradores do distrito. Os skatistas que compõem o Love CT residem em diferentes bairros de Cidade Tiradentes, logo, por conta das dinâmicas locais que imperavam na época das contendas, os seus relacionamentos poderiam ser vistos com desconfianças. Embora a possibilidade de sofrer eventuais interpelações, eles resolveram prosseguir com a amizade mediada pela prática do skate. A insistência em se apropriar dos espaços do distrito, mesmo com a instabilidade que 
reinava, proporcionou-lhes reconhecimentos e serviu de exemplo para minguar algumas atribulações que perpassavam a rotina dos moradores que se abstinham das tretas entre quebradas rivais. ${ }^{14}$ É o que detalha Marcelo Martins:

Todos os bairros da Cidade Tiradentes tinham treta uns com os outros. Só do cara colar num outro bairro, já era visto com mau olhado, os caras intimavam mesmo. Mas quando os caras começaram a ver cinco moleques andando juntos todos os dias, isso começou a equilibrar. A gente colava com todas as bancas. A gente circulava pela Cidade Tiradentes o dia inteiro, conversando com todo mundo, interagindo com todo mundo, e filmando. $\mathrm{E}$ as pessoas começaram a ter acesso ao skate de rua, com as câmeras posicionadas, e isso fez com que as pessoas prestassem atenção para o fato de que nós temos que nos apropriar do bairro onde a gente vive. Dar umas voltas, trocar ideias com as pessoas. A gente era bem-vindo em todos os lugares da Cidade Tiradentes. Pessoal recebia a gente, convidava para festa, convidava para os shows de rap, até show de forró. Começou a colar uma galera com a gente, viramos uma referência. Tinha uns caras do crime que andava, e os caras do crime que não andava. Quando começou essa parada, os caras do crime começaram a dar uma amolecida, começou a respeitar mais os caras dos outros bairros, foi bem uma construção do coletivo Love CT. (Marcelo Martins, skatista amador e educador do coletivo Love CT, entrevista em 2016)

A prática do skate contribuiu, portanto, para romper certas fronteiras estabelecidas. Como resultado os skatistas puderam conhecer melhor a região onde moram, tiveram a oportunidade de estar e ocupar espaços esquecidos por boa parte da população local, vivenciaram situações inusitadas ao se depararem com alteridades próximas, enfim, sentiram-se concomitantemente “estrangeiros” (Simmel, 1983 [1908])e acolhidos em seus próprios contextos. As negociações eram regulares e permeadas por várias artimanhas a fim de garantir a utilização dos espaços para a prática. Marcelo Martins relatou que os skatistas já disputaram, inclusive, o direito de utilizar uma quadra a partir de uma partida de futsal:

Nós temos diversas quadras de futebol espalhadas por aqui. Em décadas passadas o investimento era no futebol. E rola uma comunicação muito da hora entre a galera que está jogando bola e os skatistas. Várias vezes a gente até disputou as quadras com os moleques no futebol. Quem ganhasse a partida ficava com a quadra. A gente já ganhou uma pá de quadras com os moleques. Os caras acham que skatista não joga bola. É muito louco, pois você desconstrói um monte de coisa e constrói muitas outras, como as relações com as pessoas do bairro. Isto faz com que todos se conversem, troquem ideia, se respeitem. (Marcelo Martins, skatista amador e educador do coletivo Love CT, entrevista em 2016. Grifos meus)

\footnotetext{
${ }^{14}$ Não se pode perder de vista o fato de que muitos conflitos latentes nas periferias paulistanas foram arrefecidos a partir do aparecimento do Primeiro Comando da Capital (PCC), o qual passou a gerenciar conflitos locais e possibilitar certos direcionamentos nas dinâmicas relacionais cotidianas. Para mais informações sobre a emergência do PCC nas periferias paulistanas, ver Telles (2010), Hirata (2010), Biondi (2010) e Feltran (2012).
} 
Ao contrário do quadrante sudoeste da cidade, onde impera paisagens com melhores condições urbanísticas e onde se localizam os lugares skatáveis mais disputados pelos skatistas paulistanos, a prática do skate na Cidade Tiradentes tem que lidar com as precariedades que assolam as periferias. No entanto, ainda assim os skatistas se entusiasmam em utilizar as suas ruas e os seus respectivos equipamentos. Ao fim e ao cabo, os membros do coletivo Love CT potencializam as suas respectivas citadinidades ao enfrentarem as condições estruturais adversas do distrito com o propósito de se apropriarem dos picos que lá estão disponíveis. Anderson Lucas, em depoimento à revista Tribo Skate, desabafa:

Aqui na CT não temos os melhores picos como vemos nos vídeos de skate, porém temos os nossos próprios picos; bons ou ruins, são nossos! O fato de ter um chão áspero nos motivou ainda mais a andar de skate com garra e amor pelas tricks (manobras). (Anderson Lucas, skatista amador, depoimento concedido à Revista Tribo Skate, n. 212, 2013: 50)

“Guerreiros” e "skatistas que fazem a diferença”. Estas foram algumas das atribuições utilizadas pela revista citada para caracterizar os praticantes da Cidade Tiradentes. As asperezas dos asfaltos e as rugosidades de seus picos se contrastam com a suavidade de certas relações cotidianas estabelecidas no distrito. Enquanto nas regiões centrais de São Paulo há maior impessoalidade nas interações e maior controle dos usos da paisagem urbana, no extremo leste impera uma maior franqueza nas negociações relacionadas à prática do skate. É o que dizem os skatistas quando questionados sobre tais diferenças:

A minha ligação com a CT é muito forte, pois nasci, cresci e a maioria dos meus familiares também mora aqui, todos somos vizinhos e temos uma relação muito forte. Pelo fato de ser um bairro esquecido no quadro social em questões básicas de cidadania, as pessoas que vivem lá acabam criando um respeito muito grande uns pelos outros, e assim todos se ajudam. Dificilmente se ouve falar de brigas nas ruas ou de desrespeito, o fundamento básico do gueto é a humilde; se você vive em meio a uma comunidade precisa saber conviver com as pessoas. Todos ali são sofredores, são como panelas de pressão que a qualquer momento podem explodir. Sabendo disso o respeito e a humildade de saber chegar e sair do bairro são fundamentais no convívio: se for arrogante terá arrogância em dobro, se for simpático terá simpatia em dobro. (Anderson Lucas, skatista amador, depoimento concedido à Revista Tribo Skate, n. 212, 2013: 48-49) 
No intuito de divulgar a vivacidade do skate numa quebrada, os skatistas do Love CT tiveram a iniciativa de produzir um vídeo que retratasse os seus rolês e as suas manobras realizadas nos picos e nas pistas de Cidade Tiradentes. Intitulado Revolução Periférica, ${ }^{15}$ o vídeo começou a ser filmado a partir de 2005 e demorou cinco anos para ser concluído. Com 25 minutos de duração, a produção se divide em várias partes, sendo que em cada uma delas é enfocado algum dos membros do Love CT -Anderson Lucas, Marcelo Martins, Elton Melônio, Denis Silva e Daniel Feitosa-, bem como seus amigos. A maioria das imagens foi captada em equipamentos urbanos - corrimãos, escadas, bancos, guias, canteiros etc. - presentes em diferentes espaços da região, como escolas, creches, quadras poliesportivas, praças, calçadas, estações de ônibus e metrô, terrenos baldios, estabelecimentos comerciais e demais propriedades privadas. As técnicas corporais tão regulares ao longo de todo o vídeo são contrastadas com múltiplos tipos de experiências citadinas vivenciadas pelos protagonistas: shows de rap, sociabilidade em bares, caminhadas por vielas, brincadeiras com crianças, interações com desconhecidos. Ao se referir à produção audiovisual do Revolução Periférica, Marcelo Martins conta que:

As pessoas incentivavam a gente bastante. Não tivemos resistência das pessoas, foi algo que aproveitamos bastante. O lance de andar nos picos, a gente via nos filmes e comparava os nossos picos com os picos da Califórnia, por exemplo. Mas não chegava aos pés, pois o chão era ruim, as bordas não davam para escorregar. Isto foi bom que ajudou a nossa criatividade. Quando a gente começou a filmar o Revolução Periférica, a nossa ideia era conhecer todos os espaços da Cidade Tiradentes, poucas pessoas aqui fazem este tour, esta caminhada pelo bairro inteiro. Então muitos espaços públicos que a gente acabou descobrindo, essas pessoas não têm conhecimento. (Marcelo Martins, skatista amador e educador do coletivo Love CT, entrevista em 2016)

${ }^{15} \mathrm{O}$ vídeo pode ser visualizado em: https://www.youtube.com/watch?v=ujeAIUQwe9k. Acesso em $08 / 08 / 2016$. 


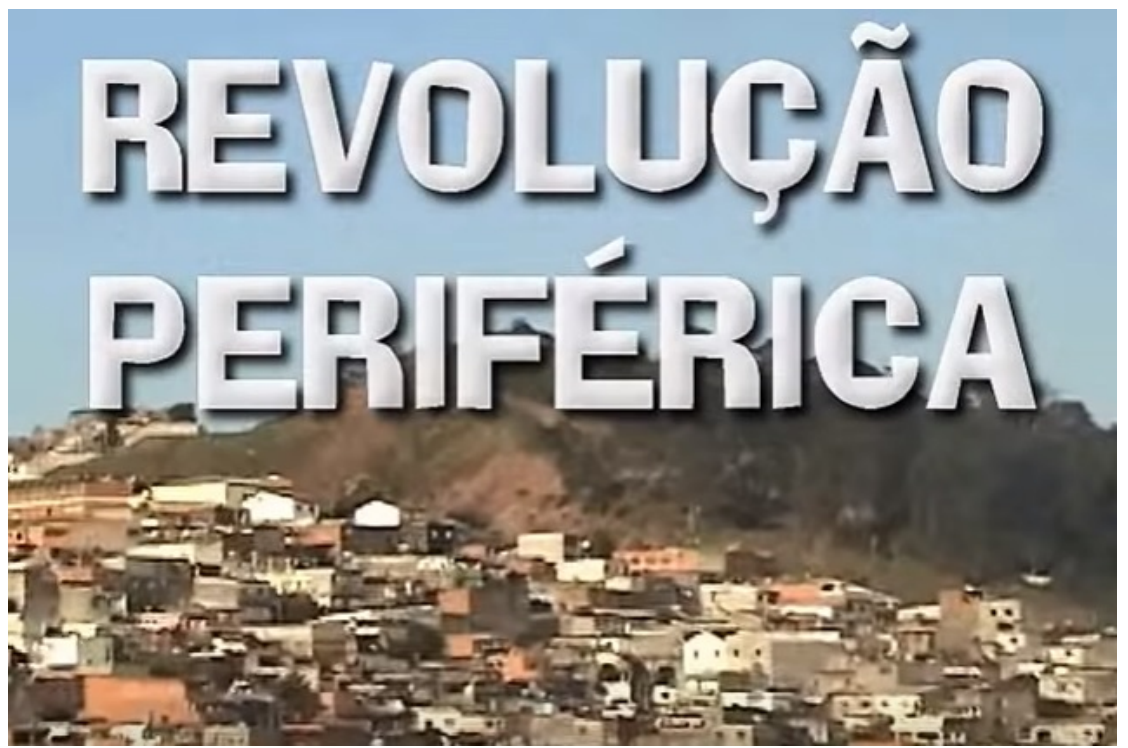

Imagem 2: Abertura do vídeo Revolução Periférica com imagens de Cidade Tiradente (Disponível em https://www.youtube.com/watch?v=ujeAIUQwe9k\&t=6s)

O lançamento do vídeo Revolução Periférica e a sua disponibilidade no YouTube contribuíram para propagar a força do skate de rua no extremo leste paulistano. Os skatistas integrantes do coletivo Love CT valorizam sobremaneira a região onde moram, conforme evidente em seus discursos, no entanto, ainda que priorizem a prática em seus próprios bairros, eles não abrem mão de circular para outros locais da Zona Leste. Além dos inúmeros picos que nela se encontram, há certos espaços públicos que são reconhecidos como pontos de encontros para praticantes oriundos de todos os seus distritos. Dentre esses espaços, em consonância ao mencionado pelos interlocutores, sobressaem-se ao menos dois - a saber, Praça da Estação e Praça Brasil - que merecem breves contextualizações.

A Praça da Estação situa-se em Itaquera, um dos distritos da Zona Leste, onde funcionava a antiga Estação Ferroviária de Itaquera. Após a desativação da ferrovia, a praça permaneceu como uma espécie de patrimônio da região que a abriga, entretanto, com o passar do tempo ela tornou-se, segundo as palavras de Mauricio Martins (subprefeito de Itaquera), “abandonada e até virou ponto de drogas”. ${ }^{16}$ Apesar de suas precariedades, uma série de ações promovidas por agentes ligados ao universo do skate transformou a Praça da Estação em um importante pico não apenas para os skatistas da

16 Depoimento concedido pelo subprefeito ao SP Notícias. Disponível em: http://spnoticias.com.br/?p=26441. Acesso em 08/08/2016. 
Zona Leste, mas também para aqueles provenientes de outras partes da cidade. Em 2011 e 2012, respectivamente, duas marcas especializadas em tênis para a prática promoveram eventos no local, deixando, como legado, alguns obstáculos de concreto para usufruto dos skatistas. ${ }^{17}$ Essa intervenção repaginou o espaço e permitiu novos tipos de apropriações em seus limites.

Os skatistas do Love CT eram frequentes na Praça da Estação. Lá andavam de skate e cotidianamente estabeleciam contatos com muitos outros praticantes. A sociabilidade tecida revelava, de acordo com as palavras de Marcelo Martins, "que a ZL [Zona Leste] se conversa, ela se respeita, ela é muito unida”. A consolidação da prática intensificou a dimensão pública da praça, logo, após a sua repercussão, novas intenções começaram a ser tramadas para o local. Uma delas seria a instalação de um Centro Gastronômico, sendo esta uma iniciativa da Câmara de Dirigentes Lojistas de Itaquera (CDLI) e do Núcleo de Desenvolvimento Sustentável de Itaquera, com o apoio da Prefeitura de São Paulo. ${ }^{18}$

Diversas modificações foram feitas na praça com vistas a construção do empreendimento comercial, assim sendo, muitos obstáculos criados para a prática do skate foram retirados ou, simplesmente, destruídos por funcionários do poder público municipal. O Centro de Gastronomia foi inaugurado em 2015 e recebeu estabelecimentos fixos e espaços para abrigar foodtrucks (carros adaptados para a venda de comidas). A sua abertura foi recebida com muito desprezo e indignação pelos skatistas de Cidade Tiradentes, bem como pelos demais da Zona Leste, visto que as práticas citadinas que ali ocorriam tornaram-se preteridas por uma rotina de consumo de diferentes tipos de comidas. À vista disso os interlocutores consideraram que esta foi, indiretamente, uma tentativa de barrar a prática do skate na Praça da Estação. Além de vídeos que contestavam a iniciativa, certos skatistas que frequentavam o pico também elaboraram um abaixo-assinado em desagravo a esta e outras atitudes fomentadas pelo subprefeito de Itaquera. No documento consta que:

O subprefeito Mauricio Luis Martins foi aos poucos expulsando os skatistas: primeiro mandou instalar um poste de iluminação bem em frente ao obstáculo mais

\footnotetext{
${ }^{17}$ Tratam-se dos eventos Converse My Square (promovido pela marca Converse Skateboard em 2011) e DC King of São Paulo (promovido pela marca DC Shoes em 2012).

18 Para mais detalhes: http://www1.folha.uol.com.br/comida/2015/04/1620759-praca-de-itaquera-eremodelada-para-virar-centro-gastronomico.shtml. Acesso em 08/08/2016.
} 
utilizado para que ninguém mais ande ali. Agora mandou retirar outros obstáculos construídos no local, como o corrimão no chão e o palco. Todos esses obstáculos foram construídos pelos skatistas sem nenhuma ajuda da subprefeitura. Atualmente os seguranças expulsam os skatistas de forma truculenta, sendo que já foram relatadas agressões aos que se atrevem a andar de skate no local. A única opção que o skatista tem em Itaquera é a Praça Estação e lá é o nosso reduto e nosso santuário. Ali é nosso único espaço de lazer e de confraternização. Por isso, nós abaixo assinados manifestamos a vontade de proteger e requerer a permanência do skate na Praça da Estação em Itaquera porque o skate revitalizou a praça e os skatistas não tem nenhuma opção para andar de skate como essa praça em nenhum outro local de Itaquera ou imediações. ("Abaixo assinado contra a proibição do skate na Praça Estação Itaquera”. Disponível em: https://www.abaixoassinado.org/abaixoassinados/30992. Acesso em 09/08/2016)

A indignação dos skatistas não surtiu efeito. Eles se colocaram como protagonistas da revitalização da praça, contudo, seus apelos foram relegados pelas lógicas de consumo impostas neste espaço do leste paulistano. A intervenção urbanística com fins econômicos concretizou-se, porém não apenas diversos picos foram minados, como também a intensidade da sociabilidade que ali ocorria. Marcelo Martins salienta que:

Os caras fizeram em Itaquera um centro gastrônomico. E aí o bagulho não deu certo. Fizeram um monte de coisa na praça que prejudicou a praça. Colocaram uma tenda grande onde fazíamos solo, onde a gente pegava embalo para andar na borda. Então cancelaram o skate, já não podia mais andar de skate no pico. E afastou todo mundo. Os skatistas usam muito pouco aquela praça. E com este negócio gastronômico, tudo ficou muito caro. Os trabalhadores não usavam ali para almoçar na hora do trampo. Pessoal só ia lá para dar um rolê com a mina, fazer rolê com a família. Era algo pontual. E aí não rolou, não foi para frente. A praça está lá hoje abandonada. (Marcelo Martins, skatista amador e educador do coletivo Love CT, entrevista em 2016)

A Praça da Estação deixou de ser uma referência para os skatistas. Desde 2015 são poucos os que se aventuram a realizar manobras nos obstáculos que lá restaram. Conforme evidente até aqui, a prática do skate de rua se vale de todo tipo de intervenção urbanística, sendo assim, picos surgem ou desaparecem à medida que a paisagem urbana é reformulada. Se por um lado os skatistas ficaram frustrados pelo cerceamento de suas manobras em Itaquera, por outro eles conseguiram se impor em outro espaço público da região quando ele ainda estava em vias de construção: trata-se da Praça Mãe Menininha do Gantois, popularmente conhecida Praça Brasil. Localizada no distrito de José Bonifácio, também na Zona Leste, o espaço é amplo e comporta em seu interior diferentes equipamentos de lazer. Entretanto, há tempos o local não passava por uma manutenção detida, assim, as suas condições estruturais limitavam certos tipos de 
apropriações. A prática do skate de rua, por exemplo, não ocorria em razão da rugosidade do piso, que dificultava a realização das manobras.

No princípio de 2016, após três anos de reformas, a Praça Brasil novamente foi entregue à população. O espaço fora reformulado, tendo ganhado plantio de árvores, internet livre, playground, aparelhos de ginástica, arena para eventos culturais etc. Conforme frisaram os integrantes do Love CT, durante o seu processo de reforma alguns skatistas locais reivindicaram aos setores competentes do poder público certas alterações nas construções que estavam sendo feitas. A ideia era adaptar determinados equipamentos a fim de que eles se tornassem skatáveis. A reivindicação foi bemsucedida, logo, a praça foi moldada para a prática do skate: corrimãos, bancos, bordas, inclinações e escadas de diferentes tamanhos passaram a compor a paisagem. Segundo Marcelo Martins,

Tem a Praça Brasil, na Cohab 2, ao lado do metrô José Bonifácio, que foi uma construção que os skatistas direcionaram a obra. Os caras estavam reformando o chão, daí eles começaram a ocupar a praça e dar pitaco. Pode colocar um corrimão aqui, uns caixotinhos ali. Daí surgiu o bagulho. A praça sempre foi muito louca, mas o chão dela muito zoado. A gente sempre falou: "se arrumar o chão vira uma plaza [skate plaza]. Não precisa de mais nada!”. Quando os caras começaram a arrumar o chão, eu e os caras [Elton e Anderson], a gente começou a filmar bastante. O cimento do chão estava secando e a gente já estava pulando as escadas. A gente ocupou o lugar. Como os caras viram isso, eles perceberam que os skatistas se apropriaram da praça. (Marcelo Martins, skatista amador e educador do coletivo Love CT, entrevista em 2016)

A mobilização de alguns skatistas surtiu efeito neste caso. A Praça Brasil tornou-se mesmo antes do término de sua reforma o novo pico de referência do leste paulistano, conquistando, então, a importância que era atribuída à Praça da Estação. Devido as suas características tangíveis e em decorrência das dinâmicas relacionais e práticas citadinas que nela se processam, a praça tem sido comparada com o principal pico de São Paulo, sendo, por isto, eventualmente chamada de "a Praça Roosevelt da Zona Leste”19. O local é palco para muitas outras iniciativas além do skate, como batalhas de rap, saraus, debates, exibição de filmes, além de comportar diversos eventos e festas em seu interior. É importante destacar que muitas das ações são fomentadas por um coletivo chamado Okupação Cultural Coragem, o qual possui certa aproximação

\footnotetext{
${ }^{19}$ Para mais detalhes sobre a prática do skate na Praça Roosevelt, em São Paulo, ver Machado (2017).
} 
com o coletivo Love $\mathrm{CT}^{20}$ O fato revela que o universo do skate não se fecha em si mesmo, pelo contrário, está aberto ao diálogo e a trocas de experiências com muitos outros universos que batalham pela apropriação dos espaços urbanos. Há, portanto, uma confluência entre diferentes “circuitos” (Magnani, 2012) estabelecidos na metrópole paulistana $^{21}$. Nessas circunstâncias o skate nas periferias revela, tal como aventado por Telles (2010: 17) ao analisar outros tipos de práticas, que a cidade é feita de cruzamentos e passagens, “é atravessada por experiências que se fazem justamente nos limiares de universos distintos, de seus pontos de conexão e das redes sociotécnicas que os atravessam e articulam em um mesmo plano de atualidade”. Quanto a isso, ao se referir aos skatistas de Cidade Tiradentes, Marcelo Martins observa que:

\begin{abstract}
O skate é muito rico. Tem o grafiteiro, o rapper, o poeta. É uma força para a juventude. Nos espaços daqui, é comum ver os skatistas na batalha de rap, é fácil você ver eles no teatro das Pombas Urbanas, no Centro de Formação Cultural. Isso é algo que está acontecendo naturalmente. Os skatistas estão frequentando os espaços, as insurgências das paradas. E tem a ver com o rolê de skate. Quando a gente vai à Praça Brasil, a gente vai andando até lá. Na volta é caminho para um rap que acontece às segundas-feiras. A gente passa num ponto de cultura e já prestigia o rap dos caras. Daí os caras reconhecem a Love CT, vê que é outro coletivo que está colando. O skate, este lado underground, este lado da arte, da música, esta aceitação cultural, é uma grande potência não só para ressignificar os espaços, mas para ocupar estes espaços. Este novo jeito de ocupar determinado espaço. (Marcelo Martins, skatista amador e educador do coletivo Love CT, entrevista em 2016)
\end{abstract}

Os integrantes do Love CT, além de se preocuparem com as suas próprias experiências, rolês, manobras e trajetórias, também se empenham em agenciar outras iniciativas cujos impactos se dão sobretudo na vida de crianças e adolescentes de Cidade Tiradentes. Tais iniciativas se passam no âmbito do projeto social que empreendem, intitulado Love CT: Inclusão e Resgate Skateboarding, que vem sendo desenvolvido desde 2010. O projeto, tal como evidente no discurso de seus realizadores, visa utilizar o skate como uma ferramenta de inclusão social, um meio para promover valores como disciplina e senso de responsabilidade entre crianças e adolescentes. É uma forma de contribuir com os seus processos educacionais, de estimular a realização

20 Mais informações sobre a Okupação Cultural Coragem encontram-se em: https://www.facebook.com/Okupa\%C3\%A7\%C3\%A3o-Cultural-Coragem-767047163428205/?fref=ts. Acesso em 08/08/2016.

${ }^{21}$ De acordo com Magnani (2012: 97), o circuito "é uma categoria que descreve o exercício de uma prática ou a oferta de determinado serviço em estabelecimentos, equipamentos e espaços que não mantêm entre si uma relação de contiguidade espacial, sendo reconhecido em seu conjunto pelos usuários habituais”. 
de uma prática corporal, de fomentar o gosto pela leitura, pelos estudos e por demais atividades culturais, como as que têm sido promovidas pelos coletivos atuantes em Cidade Tiradentes. Assim sendo, através do projeto os integrantes do Love CT acionam, estrategicamente, uma gramática política no intuito de realizar ações para crianças e adolescentes muitas vezes considerados vulneráveis. Trata-se, pois, de uma gestão social com vistas a evitar possíveis riscos (uso de drogas, inserção em redes criminais, evasão escolar etc.) que eles estariam sujeitos em seus cotidianos no distrito.

O Love CT realiza semanalmente aulas de skate que reúnem dezenas de alunos (sendo garotos e garotas) matriculados. Para que isso ocorra são utilizados equipamentos públicos situados na COHAB Inácio Monteiro, como a pista e a sede do coletivo, ambas dispostas na área externa do Centro Educacional Unificado (CEU) Inácio Monteiro ${ }^{22}$. Na pista são transmitidas as técnicas corporais que resultam em manobras. Os integrantes do coletivo atuam como professores, condição que lhes permitem ensinar aos alunos os movimentos necessários para a execução daquilo que eles chamam de base do skate, ou seja, as técnicas mais básicas. Já a sede do Love CT uma pequena casa com paredes grafitadas - regularmente reúne integrantes de outros coletivos e jovens de distintas partes do distrito para participarem das iniciativas culturais e educacionais que ali são oferecidas gratuitamente, como debates, saraus, exposições, apresentações musicais, oficinas, distribuição de lanches etc. Desse modo é possível considerar que o projeto ensina aos alunos não apenas noções básicas de cidadania - as quais são instruídas através do viés esportivo do skate (por onde circulam princípios como disciplina, respeito ao próximo, superação, preparação do corpo e da mente etc.) -, como também os instigam a reconhecer o potencial de suas citadinidades a partir da valorização de experiências que emanam da apropriação das ruas e da circulação pela cidade:

A gente apresenta teatro, artes em gerais, grafite, rap, e aí o moleque vê que a vida é um pouco mais do que o skate. Mas é a partir do skate que conseguimos passear

\footnotetext{
${ }^{22}$ Os Centros Educacionais Unificados (CEUs) são equipamentos públicos criados pela Prefeitura de São Paulo, durante a gestão da referida prefeita Marta Suplicy, localizados em áreas periféricas da cidade. De acordo com o Guia de Pistas da revista Cemporcentoskate (2006: 126), cada unidade dos CEUs tem "em média, 13 mil metros quadrados de área construída, reunindo num só espaço creche, escolas de educação infantil e ensino fundamental para 2.460 estudantes. Além disso, elas possuem infraestrutura completa para atividades esportivas, culturais e de lazer, como teatro, biblioteca, oficinas de dança e música, quadras poliesportivas, salão de ginástica, piscinas, um centro comunitário, área de lazer com pista de skate e um Telecentro com acesso gratuito à Internet e cursos de informática”.
} 
sobre tudo. É uma coisa que a gente passa para as nossas crianças, do nosso projeto. Eu falo para elas aproveitarem que estão conhecendo um novo amigo, para ir à casa dele, passear com ele, andar na pista perto da casa dele. A gente estimula isso em nosso projeto. Isto é um lado muito positivo. É uma forma de conversar mais com as pessoas. (Marcelo Martins, skatista amador e educador do coletivo Love CT, entrevista em 2016)

Os pais dos alunos passaram a frequentar as aulas para acompanhar o filho porque queriam saber o que estava acontecendo na rua que mudou tanto seu filho para melhor. Através dessa mudança na vida da criança ela acaba ganhando o incentivo da família para andar e isso já é uma grande vitória para nós! (Anderson Lucas, skatista amador, depoimento concedido à Revista Tribo Skate, n. 212, 2013: 54)

O projeto Love CT: Inclusão e Resgate Skateboarding tem impactado a vida de muitas crianças e adolescentes da Cidade Tiradentes. Há uma ampliação de seus horizontes a partir do momento em que elas se engajam nas iniciativas promovidas. Marcelo Martins relata um caso que lhe deixou orgulhoso:

As crianças que já passaram pelo projeto, eu até acompanho algumas pela internet para ver qual o impacto que o projeto causa nas ideias delas, eu acho muito louco. Estou vendo muitos moleques bem encaminhados, continuando andando de skate for fun[por diversão]. Há duas semanas, um aluno nosso, que começou com a gente em 2011, hoje ele está ingressando na faculdade. É muito louco porque o moleque entrou para fazer engenharia. E agora ele veio me dizer que trocou de faculdade, e está fazendo medicina. O mano continua andando, está estudando e trabalhando com o pai dele na feira. Os outros moleques que não têm essa história de ascensão, mas você vê que são uns moleques que cresceram mais fortes, com essa prática de exercício, com cuidado com a alimentação, você vê uns moleques grandes, fortes, da minha altura. E com umas ideias da hora. Eu não tenho nem cinco por cento de alunos que foram para as drogas após o projeto. No ambiente onde a gente vive, a cada esquina uma biqueira, a gente vê estes moleques num caminho da hora. Muitos moleques estudando, trabalhando, querendo casar. (Marcelo Martins, skatista amador e educador do coletivo Love CT, entrevista em 2016)

Os integrantes do coletivo realizam uma negociação cotidiana através de mediações com diversas esferas a fim de assegurar os rumos do projeto. Assim, eles estão a todo instante agenciando as possibilidades em vigor: buscam apoios com comerciantes locais, mobilizam a ajuda e doações de pais ou responsáveis pelos alunos, se articulam com alguns políticos, fazem apresentações em escolas públicas, reivindicam a atenção da mídia, solicitam patrocínios do mercado especializado em skate, pressionam agentes ligados ao poder público. A depender da situação eles acionam diferentes sentidos para a prática do skate: destacam a sua dimensão cidadã, o seu viés citadino, as suas frentes esportivizadas, as suas possibilidades artísticas ou culturais etc. Há, portanto, uma modulação discursiva por parte dos skatistas para 
incorporar em seus agenciamentos, ainda que de maneira pontual, a linguagem dos agentes ou das instituições que necessitam $\operatorname{lidar}^{23}$.

\section{Considerações finais}

O projeto Love CT: Inclusão e Resgate Skateboarding galgou prestígio em Cidade Tiradentes em virtude dos seus resultados alcançados. A iniciativa obteve o respaldo, inclusive, dos gestores do CEU Inácio Monteiro, os quais legitimaram, junto ao poder público municipal, a ocupação do espaço onde atualmente funciona a sede do coletivo. Desse modo, os skatistas se sujeitam a eventuais tentativas de burocratização da prática do skate, como as regulamentações que equipamentos públicos (como os CEUs) tentam impor, no entanto, o fato de acatarem certas normas não implica que as suas experiências estejam sendo domesticadas ou que uma eventual tentativa de converter uma prática citadina em uma prática esportiva esteja sendo completamente efetuada. As ações do Love CT propalam que a sociabilidade firmada entre os skatistas em Cidade Tiradentes não está sendo quebrada por lógicas estatais, ou que as suas experiências estão sendo arrefecidas pela lógica de um “empreendedorismo social”, tampouco estabilizadas apenas em espaços definidos de antemão. O coletivo revela que os sentidos da prática do skate estão sendo constantemente redefinidos e ampliados a partir do estabelecimento de "pontes comunicativas” (Aderaldo, 2013) com diversas pessoas e contextos. $^{24}$

\footnotetext{
${ }^{23}$ Uma das principais conquistas do projeto foi o financiamento obtido durante alguns anos sucessivos junto ao Programa para a Valorização de Iniciativas Culturais (VAI), iniciativa regulamentada pela prefeitura de São Paulo para apoiar financeiramente atividades artístico-culturais promovidas em regiões desprovidas de recursos e equipamentos culturais. Ademais, para incrementar os recursos os integrantes também criaram a marca Rua Pura, empreendimento cuja parte das vendas é destinada aos gastos com o projeto.

${ }^{24}$ Conforme evidenciado por Hikiji\&Caffé (2013), para alguns jovens da Cidade Tiradentes - como os envolvidos com o universo do hip hop, por exemplo -, a chegada dos CEUs representou a emergência de muros "cada vez mais altos" que impactaram a sociabilidade local que se dava nos espaços públicos do distrito. Desse modo, certos elementos deste universo - como rap, break dance e graffiti - passaram a ser incorporados e, consequentemente, burocratizados pela instituição. Na visão de alguns jovens retratados no documentário "Lá do Leste", que originou o livro de mesmo nome (organizado por ambas as autoras acima mencionadas), a emergência de muros representa uma desagregação do Hip Hop que tem culminado na "perda de sua linguagem". No caso do skate, alguns skatistas contatados eventualmente argumentavam que tais espaços gerenciados por lógicas institucionais tiram a "essência do skate" - ou seja, a prática nas ruas -, no entanto, conforme expresso neste artigo, para além de um certo distanciamento, o que as ações do coletivo Love CT demonstram é que os skatistas negociam a utilização de todos os espaços disponíveis na Cidade Tiradentes, embora valorizações diferentes sejam atribuídas a cada um deles.
} 
Foi por meio destas “pontes comunicativas”, por exemplo, que Marcelo Martins, um dos representantes do Love CT, foi convidado a compor o conselho gestor do CEU Inácio Monteiro, condição que lhe permite se posicionar em defesa das ações que desenvolve junto aos outros integrantes do coletivo:

\footnotetext{
É muito louco. Eu consegui ver nos outros conselheiros que eles valorizam muito o fato de eu estar ali. E eles me valorizam por conta do projeto social que é visível na sociedade. Eles sabem que é importante para eles, eles sabem da falta de recurso que a gente tem para o desenvolvimento do projeto. O CEU é uma coisa que está voltada diretamente ao crescimento das crianças no bairro, e isto se deve também ao trabalho do coletivo Love CT. (Marcelo Martins, skatista amador e educador do coletivo Love CT, entrevista em 2016)
}

Vale ressaltar que a iniciativa também já foi pauta de alguns meios de comunicação - como Diário de São Paulo e o Jornal SPTV (Rede Globo), por exemplo - e, inclusive, virou tema do documentário Love CT: Nunca Desista de seus Sonhos, produzido por Tristan Zumbach, videomaker e skatista suíço que teve a oportunidade de acompanhar, ao longo de algumas semanas, o cotidiano do projeto realizado no extremo leste paulistano. ${ }^{25}$

\footnotetext{
${ }^{25}$ Disponível em: https://www.youtube.com/watch?v=uJNr45S3Uvk. Acesso em 09/08/2016.
} 


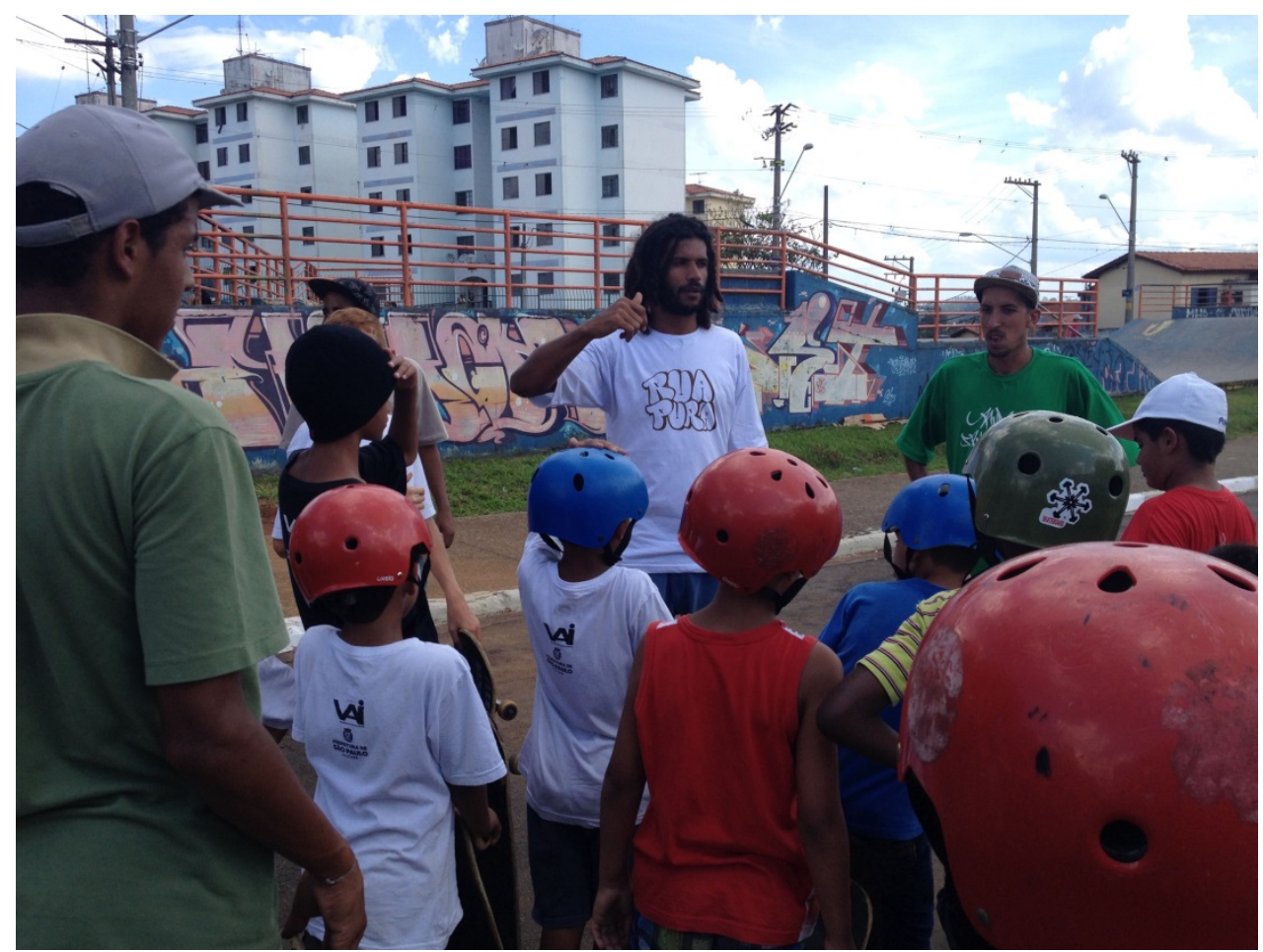

Imagem 3: Marcelo Martins e Anderson Lucas compartilham experiências com as crianças participantes das aulas de skate ofertadas pelo Love CT em Cidade Tiradentes. Marcelo Martins veste uma camiseta com os escritos Rua Pura (foto por Giancarlo Machado)

Os skatistas do Love CT, com efeito, por meio de suas manobras repolitizam os significados de uma cidadania muitas vezes almejada para jovens oriundos de camadas populares e moradores de áreas periféricas, o que não quer dizer, todavia, que eles estão a participar como profissionais da política, mas sim, como já aventado por Joseph (2004) ao analisar outras práticas citadinas, que eles cotidianamente "jogam o jogo”, isto é, que se posicionam e tomam parte em certas iniciativas que estão sendo executadas, além de agenciarem suas próprias demandas. Nesse sentido as ações do Love CT expõem que os skatistas se prostram como sujeitos de direitos e que, outrossim, através de suas “sociabilidades alargadas” (Agier, 1999) e das associações que eles provocam entre elementos heterogêneos, a própria “noção de 'periferia' deixa de ser vista como um simples espaço marcado pela carência para se constituir como o lócus de fabricação da própria cidade” (Aderaldo, 2013: 96). ${ }^{26}$

\footnotetext{
${ }^{26}$ Os pressupostos de Aderaldo (2013) se valem de sua etnografia realizada com coletivos culturais atuantes nas periferias paulistanas. Embora o foco de tal autor sejam jovens envolvidos com produções audiovisuais, as suas considerações se aproximam do contexto etnográfico investigado para fins do presente artigo.
} 


\section{Referências}

ADERALDO, Guilhermo. Reinventando a "cidade": disputas simbólicas em torno da produção e exibição audiovisual de “coletivos culturais” em São Paulo. Tese (doutorado em Antropologia Social). Faculdade de Filosofia, Letras e Ciências Humanas da USP, São Paulo, 2013.

AGIER, Michel. L'invention de la ville. Paris: Ed. desArchivesContemporaines, 1999.

BARONE, Ana Cláudia Castilho. "Periferia como questão: São Paulo na década de 1970”. Revista do Programa de Pós-Graduação em Arquitetura e Urbanismo da FAUUSP, v. 20, n. 33, pp. 64-85, 2013.

BIONDI, Karina. Junto e misturado: uma etnografia do PCC. São Paulo: Terceiro Nome, 2010.

D’ANDREA, Tiarajú. A formação dos sujeitos periféricos: cultura e política na periferia de São Paulo. Tese (doutorado em Sociologia) - Faculdade de Filosofia, Letras e Ciências Humanas. Universidade de São Paulo, São Paulo, 2013.

FELTRAN, Gabriel de Santis. Desvelar a política na periferia: histórias de movimentos sociais em São Paulo. São Paulo: Humanitas/FAPESP, 2005.

Fronteiras de tensão: política e violência nas periferias de São Paulo. São Paulo: Editora Unesp/CEM, 2011.

"Governo que produz crime, crime que produz governo: o dispositivo de gestão do homicídio em São Paulo (1992-2011)”. Revista Brasileira de Segurança Pública, v. 6, pp. 232-255, 2012.

HIRATA, Daniel Veloso. Sobreviver na adversidade: entre o mercado e a vida. Tese (doutorado em Sociologia) - Faculdade de Filosofia, Letras e Ciências Humanas. Universidade de São Paulo, São Paulo, 2010.

HIKIJI, Rose SatikoGitirana; Caffé, Carolina. Lá do Leste - Uma etnografia audiovisual compartilhada. São Paulo, Humanitas, 2013.

JOSEPH, Isaac.“Belém: paisagem, coisa pública”. Cadernos Ippur. Rio de Janeiro, v. 18, n. 1/2, pp. 41-90, 2004.

MACHADO, Giancarlo Marques Carraro. De “carrinho” pela cidade: a prática do skate em São Paulo. São Paulo: Editora Intermeios/FAPESP, 2014.

. A cidade dos picos: a prática do skate e os desafios da citadinidade. Tese (doutorado em Antropologia Social) - Faculdade de Filosofia, Letras e Ciências Humanas. Universidade de São Paulo, São Paulo, 2017.

MAGNANI, José Guilherme C. Da periferia ao centro: trajetórias de pesquisas em Antropologia Urbana. São Paulo: Terceiro Nome, 2012.

MAGNANI, José Guilherme C.; SOUZA, Bruna Mantese (orgs.). Jovens na metrópole: etnografias de circuitos de lazer, encontro e sociabilidade. São Paulo: Terceiro Nome, 2007. 
NASCIMENTO, Érica Peçanha. É tudo nosso! Produção e consumo cultural na periferia paulistana. Tese (doutorado em Antropologia Social) - Faculdade de Filosofia, Letras e Ciências Humanas. Universidade de São Paulo, São Paulo, 2011. PEREIRA, Alexandre Barbosa. "Pichando a cidade: apropriações 'impróprias' do espaço urbano”. In: MAGNANI, José Guilherme C.; SOUZA, Bruna Mantesede (Orgs.). Jovens na metrópole: etnografias de circuitos de lazer, encontro $e$ sociabilidade. São Paulo: Terceiro Nome, 2007, pp. 225-246.

ROLNIK, Raquel; FRÚGOLI JR., Heitor. "Reestruturação urbana da metrópole paulistana: a Zona Leste como território de rupturas e permanências”. Cadernos Metrópole, São Paulo, n. 6, pp. 55-83, 2001.

SIMMEL, Georg. "O estrangeiro”. In: MORAES, Evaristo (Org.). Sociologia: Simmel. São Paulo: Ática, 1983 [1908].

SPAGGIARI, Enrico. Família joga bola: constituição de jovens futebolistas na várzea paulistana. Tese (doutorado em Antropologia Social, Faculdade de Filosofia, Letras e Ciências Humanas). Universidade de São Paulo, São Paulo, 2015.

TELLES, Vera da Silva. As cidadesnasfronteiras do legal e do ilegal. Belo Horizonte:Argumentum, 2010.

TELLES, Vera da Silva; CABANNES, Robert (orgs.). Nas tramas da cidade, trajetórias urbanas e seusterritórios. São Paulo:Humanitas, 2006.

TOLEDO, Luiz Henrique de. “Quase lá: a Copa do Mundo no Itaquerão e os impactos de um megaevento na socialidade torcedora”. Horizontes Antropológicos, ano 19, n. 40, pp. 149-184, 2013.

\section{Matérias de imprensa}

ABAIXO ASSINADO. “Abaixo assinado contra a proibição do skate na Praça Estação Itaquera”, 26/06/2015. Disponível em: https://www.abaixoassinado.org/abaixoassinados/30992. Acesso em 09/08/2016.

FOLHA DE SÃO PAULO. "Praça de Itaquera é remodelada para virar centro gastronômico”. Folha de São Paulo, 24/04/2015. Disponível em: http://www1.folha.uol.com.br/comida/2015/04/1620759-praca-de-itaquera-eremodelada-para-virar-centro-gastronomico.shtml. Acesso em 08/08/2016. GUIA DE PISTAS. Revista CemporcentoSkate, edição especial, 2006.

GUIMARÃES, Juca. "Praça da Estação abriga novo centro gastronômico". SP Notícias, 26/04/2015. Disponível em: http://spnoticias.com.br/?p=26441. Acesso em 08/08/2016. MUG, Marcelo. “Love CT”. Revista Tribo Skate, n. 212, 2013.

PREFEITURA DE SÃO PAULO. "Programa VAI”. Portal da Prefeitura de São Paulo. Disponível em: http://www.prefeitura.sp.gov.br/cidade/secretarias/cultura/fomentos/index.php?p=7276. Acesso em 15/08/2016. 


\section{Documentários}

CAUSANDO NA RUA. Episódio Trajeto Urbano Encontra Inclusão e Resgate por Raphael Escobar e Love CT. Direção: Tata Amaral. Brasil, 2016, 26 min.

LOVE CT: NUNCA DESISTA DOS SEUS SONHOS. Direção: Tristan Zumbach. Suíça, 2014, 5 min.

REVOLUÇÃO PERIFÉRICA. Direção: Anderson Lucas e Elton Melonio. Brasil, 2010, 25 min.

\section{Sites consultados}

http://cohab.sp.gov.br

https://facebook.com/ruapura.skateshop 